Check for updates

Cite this: Chem. Sci., 2019, 10, 90

๑ All publication charges for this article have been paid for by the Royal Society of Chemistry

Received 29th August 2018

Accepted 25th September 2018

DOI: $10.1039 / \mathrm{c} 8 \mathrm{sc} 03858 \mathrm{a}$

rsc.li/chemical-science

\section{Multiple adaptation of constitutional dynamic networks and information storage in constitutional distributions of acylhydrazones $\uparrow$}

\author{
Guangwen Men ${ }^{\mathrm{ab}}$ and Jean-Marie Lehn (D) *a
}

\section{Introduction}

Along the path towards systems of increasing complexity, ${ }_{1}^{1}$ constitutional dynamic chemistry ${ }^{2}$ confers to chemistry a fifth dimension, that of constitution, in addition to the three dimensions of space (structure) and that of time (kinetics) ${ }^{2 b}$ It is based on the generation of constitutional dynamic libraries (CDLs), that may be represented in terms of constitutional dynamic networks (CDNs) $)^{1 d, 2 b-2 d, 3,4}$ interconnecting the constituents through agonistic and antagonistic relationships. ${ }^{1,2 b-2 d, 3}$ The CDNs may be considered to express chemical information residing in a specific distribution of constituents, represented by a constitutional engram ${ }^{2 b, 2 d}$ subject to and characteristic of environmental/external perturbations. In this respect, CDNs give access to chemical systems that may be trained and present higher levels of behavior displaying processes of storage, recall, and erasing of information in response, for instance, to chemical effectors such as one or two metal ions. ${ }^{3 g}$ The simplest CDNs are formed by four constituents subject to the exchange of their components in a square $[2 \times 2]$ network. Higher order CDNs beyond the $[2 \times 2]$ case, namely, network of networks and $[3 \times 3]$ networks, have been shown to present novel features

${ }^{a}$ Laboratoire de Chimie Supramoléculaire, Institut de Science et d'Ingénierie Supramoléculaires, Université de Strasbourg, 8 allée Gaspard Monge, 67000 Strasbourg, France. E-mail: lehn@unistra.fr; Fax: + 333688551 40; Tel: +33 368 855144

${ }^{b}$ State Key Laboratory of Supramolecular Structure and Materials, Jilin University, 2699 Qianjin Avenue, Changchun, 130012, P. R. China

$\dagger$ Electronic supplementary information (ESI) available. See DOI: 10.1039/c8sc03858a such as multiple, synergistic and competitive hierarchical adaptation. $^{3 k}$ A further step towards systems ${ }^{5}$ of higher complexity consists of devising CDNs that would alternatively respond to multiple external perturbing agents with orthogonal features beyond two effectors, so that it may be driven along different pathways to express multiple distribution patterns, representing multiple processing of information and leading to different informational states.

According to our previous works, ${ }^{6}$ pyridyl-acylhydrazones (PyAHs) derived from the reaction of hydrazides with 2-pyridine carboxaldehyde exhibit appealing triple dynamic processes, as they are able to undergo the following: (1) constitutional dynamics by exchange of the amine and/or carbonyl component through reversible transamination; ${ }^{1}$ (2) reversible metal cation binding and exchange as well as deprotonation dynamics, stemming from the tridentate NNO coordination site; ${ }^{7}$ (3) configurational dynamics by photo- and thermo-induced cis-trans $(E / Z)$ isomerization at the $\mathrm{C}=\mathrm{N}$ double bond. ${ }^{8}$ However, compared to the mixed systems (comprising imines, hydrazones, acylhydrazones, etc.), the development of multi-adaptive CDNs based solely on acylhydrazone constituents and responding to diverse perturbing agents (metal ions, acid/base, light, for instance) is still challenging due to factors such as the kinetic inertia of component exchange, low specificity of metal ion binding, inefficient conversion of photoisomerization, etc.

Herein, we demonstrate four $[2 \times 2]$ dynamic covalent libraries (DCLs) ${ }^{9}$ based on four acylhydrazone constituents ${ }^{\mathbf{a}} \mathbf{A}^{\mathbf{b}} \mathbf{B}$ (shown in Chart 1) capable of adapting to three orthogonal external agents (base, metal ions and light), through triple dynamic selection processes, respectively, coupled 
'A'B: $\mathrm{X}=\mathrm{N}, \mathrm{Y}=\mathrm{CH}_{3}, \mathrm{Z}=\mathrm{H}, \mathrm{R}=\mathrm{N}\left(\mathrm{CH}_{3}\right)_{2}$ ${ }^{1} \mathbf{A}^{2} \mathrm{~B}: \mathrm{X}=\mathrm{N}, \mathrm{Y}=\mathrm{CH}_{3}, \mathrm{Z}=\mathrm{H}, \mathrm{R}=\mathrm{H}$ 'A $\mathrm{A}^{3} \mathrm{~B}: \mathrm{X}=\mathrm{N}, \mathrm{Y}=\mathrm{H}, \mathrm{Z}=\mathrm{H}, \mathrm{R}=\mathrm{N}\left(\mathrm{CH}_{3}\right)_{2}$

'A ${ }^{4} \mathrm{~B}: \mathrm{X}=\mathrm{N}, \mathrm{Y}=\mathrm{H}, \mathrm{Z}=\mathrm{H}, \mathrm{R}=\mathrm{OCH}_{3}$

${ }^{2} A^{5} B: X=N, Y=H, Z=H, R=H$

${ }^{1} \mathbf{A}^{6} \mathbf{B}: \mathrm{X}=\mathrm{N}, \mathrm{Y}=\mathrm{H}, \mathrm{Z}=\mathrm{H}, \mathrm{R}=\mathrm{Cl}$

'A $\mathbf{A}$ : $X=\mathrm{N}, \mathrm{Y}=\mathrm{H}, \mathrm{Z}=\mathrm{H}, \mathrm{R}=\mathrm{CF}_{3}$

${ }^{2} \mathrm{~A}^{1} \mathrm{~B}: \mathrm{X}=\mathrm{N}, \mathrm{Y}=\mathrm{CH}_{3}, \mathrm{Z}=\mathrm{CH}_{2} \mathrm{OCH}_{3}, \mathrm{R}=\mathrm{N}\left(\mathrm{CH}_{3}\right)_{2} \quad{ }^{4} \mathrm{~A}^{\prime} \mathrm{B}: \mathrm{X}=\mathrm{CH}, \mathrm{Y}=\mathrm{CH}_{3}, \mathrm{Z}=\mathrm{OCH}_{3}, \mathrm{R}=\mathrm{N}\left(\mathrm{CH}_{3}\right)_{2}$

${ }^{2} \mathrm{~A}^{8} \mathrm{~B}: \mathrm{X}=\mathrm{N}, \mathrm{Y}=\mathrm{H}, \mathrm{Z}=\mathrm{CH}_{2} \mathrm{OCH}_{3}, \mathrm{R}=\mathrm{NO}_{2} \quad{ }^{4} \mathrm{~A}^{3} \mathrm{~B}: \mathrm{X}=\mathrm{CH}, \mathrm{Y}=\mathrm{H}, \mathrm{Z}=\mathrm{OCH}_{3}, \mathrm{R}=\mathrm{N}\left(\mathrm{CH}_{3}\right)_{2}$

${ }^{3} \mathbf{A}^{1} \mathbf{B}: \mathrm{X}=\mathrm{CH}, \mathrm{Y}=\mathrm{CH}_{3}, \mathrm{Z}=\mathrm{OCH}_{2} \mathrm{CH}_{3}, \mathrm{R}=\mathrm{N}\left(\mathrm{CH}_{3}\right)_{2} \quad{ }^{4} \mathrm{~A}^{5} \mathbf{B}: \mathrm{X}=\mathrm{CH}, \mathrm{Y}=\mathrm{H}, \mathrm{Z}=\mathrm{OCH}_{3}, \mathrm{R}=\mathrm{H}$

${ }^{3} \mathbf{A}^{8} \mathbf{B}: \mathrm{X}=\mathrm{CH}, \mathrm{Y}=\mathrm{H}, \mathrm{Z}=\mathrm{OCH}_{2} \mathrm{CH}_{3}, \mathrm{R}=\mathrm{NO}_{2} \quad{ }^{4} \mathbf{A}^{7} \mathbf{B}: \mathrm{X}=\mathrm{CH}, \mathrm{Y}=\mathrm{H}, \mathrm{Z}=\mathrm{OCH}_{3}, \mathrm{R}=\mathrm{CF}_{3}$

Chart 1 Structures of the acylhydrazones ${ }^{\mathrm{a}} \mathrm{A}^{\mathrm{b}} \mathrm{B}$ obtained by condensation of the corresponding aldehydes and hydrazides. The fragments originating from the aldehyde components are designated by the letter A and those from the hydrazides by the letter B.

base-metalloselection, metalloselection and photoselection. These four DCLs, as well as their triple external perturbations, could be specifically identified by means of the overall distributions of constituents within their CDNs. The size of the colored "balls" in the $[2 \times 2]$ square networks, shown in the schemes below, gives a gross representation of the relative amounts of the four constituents. The present work reconsiders an earlier study involving acylhydrazone-based $\mathrm{CDNs}^{3 d}$ and achieves the switching between orthogonal metalloselection and photoselection processes. It provides a proof of principle of the ability of chemical systems of increasing complexity to display higher levels of information processing including ternary outputs under triple binary inputs.

\section{Results and discussion}

\section{Design and construction of the acylhydrazone-based DCLs from suitably selected components and catalysts}

1.1. Component selection. DCLs of acylhydrazones ${ }^{\mathbf{a}} \mathbf{A}^{\mathbf{b}} \mathbf{B}$ were generated by the reaction of pyridine-2-carboxaldehyde $\left({ }^{\mathbf{p}} \mathbf{A}\right)$ or benzaldehyde $\left({ }^{\mathbf{b}} \mathbf{A}\right)$ derivatives with hydrazides. The former are required for the generation of an NNO tridentate coordination site for metal cation binding as well as for providing an $\mathrm{N}$ site for intramolecular hydrogen bonding with the $\mathrm{N}-\mathrm{H}$ site of the hydrazide derived group.

Several para substituted benzhydrazides were studied in order to modulate the electronic properties of the acylhydrazone unit. The $N$-methylated benzhydrazide ${ }^{\mathbf{1}} \mathbf{B}$ was selected first since its electron donating group ( $p$-dimethylamino, EDG) would be expected to increase the electron density on the carbonyl group thus increasing metal cation binding ability ${ }^{3 e}$ (Scheme 1, left bottom). The other hydrazide components investigated were the non-methylated $\mathrm{N}-\mathrm{H}$ ones ${ }^{\mathbf{h}} \mathbf{B}$ bearing four options of para $\mathrm{R}$ groups, $\mathrm{NO}_{2}, \mathrm{CF}_{3}, \mathrm{H}$ and $\mathrm{N}\left(\mathrm{CH}_{3}\right)_{2}$.

The reaction between these ${ }^{\mathbf{a}} \mathbf{A}$ and ${ }^{\mathbf{b}} \mathbf{B}$ components was used to generate the DCLs constructing the CDNs NA-ND. The generation of the DCLs by the formation of the acylhydrazone functional group as well as the component exchange between constituents occur faster with the pyridine-2-carboxaldehyde components $\left({ }^{\mathbf{p}} \mathbf{A}\right)$ than with the benzaldehyde components $\left({ }^{\mathbf{b}} \mathbf{A}\right)$ (see also ref. 10a).

The introduction of $\mathrm{Z}$ and $\mathrm{Z}^{\prime}$ groups on ${ }^{\mathbf{p}} \mathbf{A}$ and ${ }^{\mathbf{b}} \mathbf{A}$, respectively, was solely dependent on the $\mathrm{R}$ group on ${ }^{\mathbf{h}} \mathbf{B}$, in order to

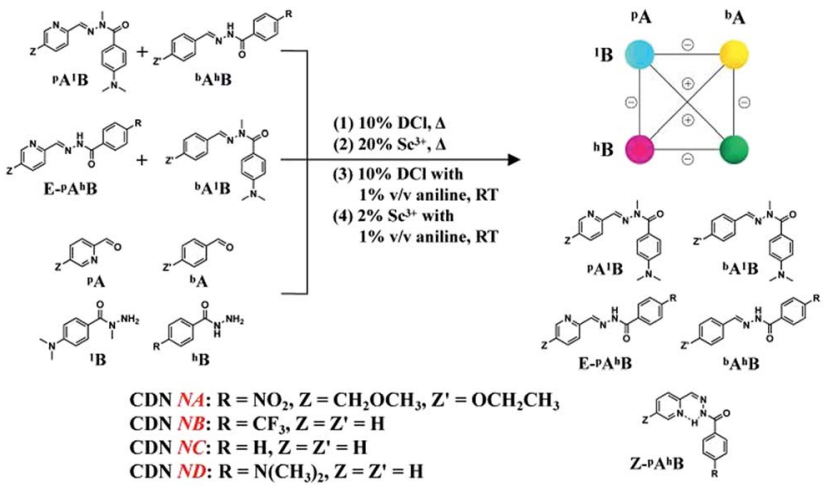

Scheme 1 Generation of four [2 $\times 2$ 2] CDNs with four constituents ${ }^{\mathrm{p}} \mathrm{A}^{1} \mathrm{~B},{ }^{\mathrm{b}} \mathrm{A}^{1} \mathrm{~B},{ }^{\mathrm{p}} \mathrm{A}^{\mathrm{h}} \mathrm{B}$ and ${ }^{\mathrm{b}} \mathrm{A}^{\mathrm{h}} \mathrm{B}$ (3.5 $\mathrm{mM}$ each) by component exchange between either ${ }^{\mathrm{p}} A^{1} B$ and ${ }^{\mathrm{b}} A^{\mathrm{h}} B$ (left top) or ${ }^{\mathrm{p}} A^{\mathrm{h}} B$ and ${ }^{\mathrm{b}} A^{1} B$ (left middle), or by component condensation of ${ }^{\mathrm{P}} \mathrm{A},{ }^{\mathrm{b}} \mathrm{A},{ }^{1} \mathrm{~B}$ and ${ }^{\mathrm{h}} \mathrm{B}$ with different catalyst and temperature conditions, giving the same statistical distribution. ${ }^{\mathrm{P}} \mathrm{A}^{\mathrm{h}} \mathrm{B}$ exist in both $E$ and $Z$ isomers. The diagonals and edges of the square link agonistic (+) and antagonistic (-) constituents, respectively.

provide overall solubility of components and constituents in $\mathrm{CD}_{3} \mathrm{CN}$. The sets of four acylhydrazones were formed either by randomization from a 1:1 mixture of two preformed constituents (Scheme 1, left top and middle) or by reaction between four corresponding components.

1.2. Acid or metal ion catalysis. Although the $\mathrm{C}=\mathrm{N}-\mathrm{N}$ conjugation of acylhydrazones decreases the electrophilicity of the $\mathrm{C}=\mathrm{N}$ bond, the carbonyl group is likely to reduce this conjugation, making the $\mathrm{C}=\mathrm{N}$ group more reactive towards nucleophiles or water as compared to hydrazone. ${ }^{3 e}$ The stability of the acylhydrazone linkage is influenced by several external factors. As expected, the formation and exchange reactions of acylhydrazones can be significantly sped up by means of acid catalysis and temperature increase..$^{\boldsymbol{b}, \mathbf{1 0 b}}$ For example, one equiv. (7 mM) of each component, ${ }^{2} \mathbf{A},{ }^{3} \mathbf{A},{ }^{\mathbf{1}} \mathbf{B}$ and ${ }^{\mathbf{8}} \mathbf{B}$, was mixed with $10 \% \mathrm{DCl}$ as the acid catalyst in $\mathrm{CD}_{3} \mathrm{CN}$. After equilibration by heating to $60{ }^{\circ} \mathrm{C}$ for $5 \mathrm{~h}$, the DCL was cooled and subjected to ${ }^{1} \mathrm{H}$ NMR measurement for the analysis of the composition of the mixture of compounds generated. The results indicated that the full set of ${ }^{\mathbf{2}} \mathbf{A}^{\mathbf{1}} \mathbf{B},{ }^{\mathbf{3}} \mathbf{A}^{\mathbf{1}} \mathbf{B},{ }^{\mathbf{2}} \mathbf{A}^{\mathbf{8}} \mathbf{B}$ and ${ }^{\mathbf{3}} \mathbf{A}^{\mathbf{8}} \mathbf{B}$ (network NA, $\mathrm{R}=\mathrm{NO}_{2}$, $3.5 \mathrm{mM}$ each) was formed from condensation, transimination, hydrolysis, and recondensation of the respective $\mathbf{A}$ and $\mathbf{B}$ components, with a statistical distribution (represented by a weighted graph of a square network, Scheme 1 right top) of $25 \% / 25 \% / 25 \%$ ( $E: 10 \%, Z: 15 \%) / 21 \%$ as well as $3 \%$ of hydrolysis (Table $\mathrm{S} 1, \dagger$ top left), wherein ${ }^{2} \mathbf{A}^{\mathbf{8}} \mathbf{B}$ was present as both $E$ - and $Z$ isomers. The same distribution was obtained starting from a pair of constituents, either ${ }^{\mathbf{2}} \mathbf{A}^{\mathbf{1}} \mathbf{B}$ and $E_{-}^{-2} \mathbf{A}^{\mathbf{8}} \mathbf{B}$ or ${ }^{\mathbf{3}} \mathbf{A}^{\mathbf{1}} \mathbf{B}$ and ${ }^{3} \mathbf{A}^{\mathbf{8}} \mathbf{B}$ under similar conditions (with a somewhat longer heating time of at least $54 \mathrm{~h}$ ). One may note that herein the thermoisomerization from $E$ to $Z$-isomer of ${ }^{2} \mathbf{A}^{\mathbf{8}} \mathbf{B}$ occurred in the exchange case of ${ }^{2} \mathbf{A}^{\mathbf{1}} \mathbf{B}$ and $E_{-}^{-2} \mathbf{A}^{\mathbf{8}} \mathbf{B}$, presumably due to the stabilization of the $Z$ form by intramolecular $\mathrm{N}-\mathrm{H} \cdots \mathrm{N}$ (pyridyl) $\mathrm{H}$-bonding. Moreover, in the other cases NB, NC and ND, acid catalysis was even more efficient, leading to shorter equilibration time (Tables S2-S4, Fig. S8a-10a, $\dagger$ from NB-1 to ND-1), 
especially in the network ND (no more than $13 \mathrm{~h}$ ) with the electron donating $\mathrm{R}$ group, probably because the $\mathrm{N}(\mathrm{Me})_{2}$ group increased the nucleophilicity of the $-\mathrm{NH}_{2}$ group in the hydrazide part.

The generation of the four DCLs constructing the four CDNs, NA-ND, could also be catalyzed in the same conditions by the addition of $20 \%$ scandium triflate instead of $10 \% \mathrm{DCl}$. In this case, all the CDNs retained statistical distributions of the constituents, albeit producing higher percentages of $E$-isomers of each ${ }^{\mathbf{P}} \mathbf{A}^{\mathbf{h}} \mathbf{B}$ presumably due to their binding with $\mathrm{Sc}^{3+}$ during the generation of libraries (Tables $\mathrm{S} 1-\mathrm{S} 4, \dagger$ left middle, from NA2 to ND-2).

Organocatalysis by aniline acting as a nucleophilic catalyst has been described for hydrazone formation ${ }^{\mathbf{1 0 , 1 1}}$ However, as shown in Scheme $\mathrm{S} 2, \uparrow$ the fabrication of the aforementioned DCLs using a large amount $(1 \% \mathrm{v} / \mathrm{v})$ of the aniline catalyst was less than successful: either it did not work at all from two synthesized constituents or required long reaction times.

1.3. Combination of catalysts. Since such acylhydrazonebased DCLs could benefit from the application of an appropriate catalyst to achieve thermodynamic control under mild conditions, combinations of acid/metal ion and organocatalyst were explored for their formation. When equimolar amounts of ${ }^{\mathbf{P}} \mathbf{A},{ }^{\mathbf{b}} \mathbf{A},{ }^{\mathbf{1}} \mathbf{B}$ and ${ }^{\mathbf{b}} \mathbf{B}$ were reacted in the presence of $10 \% \mathrm{DCl}$ and $1 \% \mathrm{v} / \mathrm{v}$ aniline, the equilibrium could be reached within 14 hours at room temperature. Another pair of catalysts, $2 \% \mathrm{Sc}^{3+}$ and $1 \% \mathrm{v} / \mathrm{v}$ aniline, also provided mild conditions at ambient temperature.

\section{2. $\mathrm{Zn}^{2+}$ binding competition and transfer among pyridyl- acylhydrazones}

Various divalent metal cations, such as $\mathrm{Zn}^{2+}$, are known to form stable octahedral complexes with PyAHs by coordination to their NNO tridentate site, ${ }^{\mathbf{1 2}}$ which is a weaker and more labile binder than an NNN site formed by pyridyl-hydrazone ligands. Thus, these metal ions are expected to be selectively captured and controllably transferred by PyAHs with NNO units presenting different metal ion affinities by means of modifying the interaction strength of the carbonyl $O$ site with metal ions through the para-substituent $\mathrm{R}$ on the hydrazide moiety (Chart 1). In order to design the DCLs of acylhydrazones under metalloselection, we conducted a systematic study of the effect of the substitution on $\mathrm{Zn}^{2+}$ competitions among the PyAHs.

In order to investigate the relative coordination affinities towards $\mathrm{Zn}^{2+}$ between $\mathrm{N}-\mathrm{H}$ PyAHs and $\mathrm{N}$-methylated PyAHs $\left({ }^{\mathbf{P}} \mathbf{A}^{\mathbf{h}} \mathbf{B}\right.$ and ${ }^{\mathbf{P}} \mathbf{A}^{\mathbf{1}} \mathbf{B}$ ), a $1 / 1$ mixture of ${ }^{\mathbf{1}} \mathbf{A}^{\mathbf{1}} \mathbf{B}$ and ${ }^{\mathbf{1}} \mathbf{A}^{\mathbf{3}} \mathbf{B}$ (3.5 mM each) was treated with 0.5 equiv. of $\mathrm{Zn}^{2+}$. After equilibrating by heating at $60{ }^{\circ} \mathrm{C}$ for $6 \mathrm{~h}$, the mixture was cooled and subjected to lowtemperature $\left(-30{ }^{\circ} \mathrm{C}\right){ }^{1} \mathrm{H}$ NMR measurement for the quantitative evaluation of the composition, in particular, $\mathrm{Zn}^{2+}$ distribution between these two ligands. The analysis of the NMR spectra showed that most of the $\mathrm{Zn}^{2+}$ was trapped in the formation of the homoleptic complexes $\mathrm{Zn}^{\mathrm{II}}\left({ }^{\mathbf{1}} \mathbf{A}^{\mathbf{1}} \mathbf{B}\right)_{2}$ and $\mathrm{Zn}^{\mathrm{II}}\left({ }^{1} \mathbf{A}^{\mathbf{3}} \mathbf{B}\right)_{2}$, as well as the mixed ligand complex $\mathrm{Zn}^{\mathrm{II}}\left({ }^{\mathbf{1}} \mathbf{A}^{\mathbf{1}} \mathbf{B}\right.$, ${ }^{1} \mathbf{A}^{\mathbf{3}} \mathbf{B}$ ), which was confirmed by ESI mass spectrometric analysis (Fig. S12b †). After further composition analysis of this mixture, a remarkable difference in the metal ion binding ability of the aforementioned ligands was found: the $\mathrm{N}-\mathrm{H}$ derived acylhydrazone ${ }^{\mathbf{1}} \mathbf{A}^{\mathbf{3}} \mathbf{B}$ captured $89 \%$ of the total $\mathrm{Zn}^{2+}$ ions compared to only $11 \%$ of those for the $N$-methylated derived acylhydrazone ${ }^{\mathbf{1}} \mathbf{A}^{\mathbf{1}} \mathbf{B}$ (Schemes 2a and S4 $\dagger$ ), indicating that methylation on the hydrazide moiety of PyAHs decreased the coordination strength with metal ions. Conversely, in a $1 / 1$ mixture of ${ }^{\mathbf{1}} \mathbf{A}^{\mathbf{1}} \mathbf{B}$ and ${ }^{\mathbf{1}} \mathbf{A}^{\mathbf{2}} \mathbf{B}$ (3.5 mM each) with 0.5 equiv. of $\mathrm{Zn}^{2+}$, as shown in Schemes $2 \mathrm{~b}$ and $\mathrm{S} 3, \uparrow$ there is a significant preference for $\mathrm{Zn}^{2+}$ ion binding to ${ }^{\mathbf{1}} \mathbf{A}^{\mathbf{1}} \mathbf{B}$ (85\%) bearing an electron donor para-dimethylamino group, attributed to an increase in the basicity of the carbonyl and therefore the strength of its interaction with a metal ion. The results above demonstrate that the metal ion binding abilities of PyAHs are remarkably structure-dependent and can be regulated by the rational choice of the $\mathrm{Y}$ and $\mathrm{R}$ groups on the hydrazide side.

When a $\mathbf{1 / 1}$ mixture of ${ }^{\mathbf{1}} \mathbf{A}^{\mathbf{1}} \mathbf{B}$ and ${ }^{\mathbf{1}} \mathbf{A}^{\mathbf{5}} \mathbf{B}$ (3.5 mM each) was treated with 0.5 equiv. of $\mathrm{Zn}^{2+}$, an almost equal distribution of $\mathrm{Zn}^{2+}$ between ${ }^{\mathbf{1}} \mathbf{A}^{\mathbf{1}} \mathbf{B}$ (45\%) and ${ }^{\mathbf{1}} \mathbf{A}^{\mathbf{5}} \mathbf{B}$ (55\%) was obtained, showing no significant preference for either coordination site (Scheme $\mathrm{S} 6 \dagger)$. Interestingly, one can readily regulate the $\mathrm{Zn}^{2+}$ distribution between $\mathrm{N}$-methylated and $\mathrm{N}-\mathrm{H}$ PyAHs by introducing different $\mathrm{R}$ groups on $\mathrm{N}-\mathrm{H}$ PyAHs (Schemes 2c, S4-S8 $\dagger$ ), whereby most of the $\mathrm{Zn}^{2+}$ ions were located in complexes with $\mathrm{N}-\mathrm{H}$ PyAHs bearing electron-donating groups $\left(\mathrm{R}=\mathrm{N}\left(\mathrm{CH}_{3}\right)_{2}\right.$ or

(a)

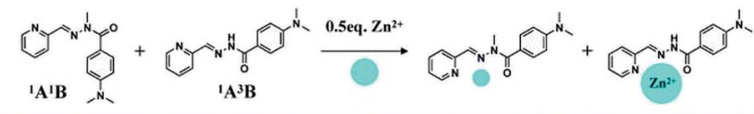

(b)
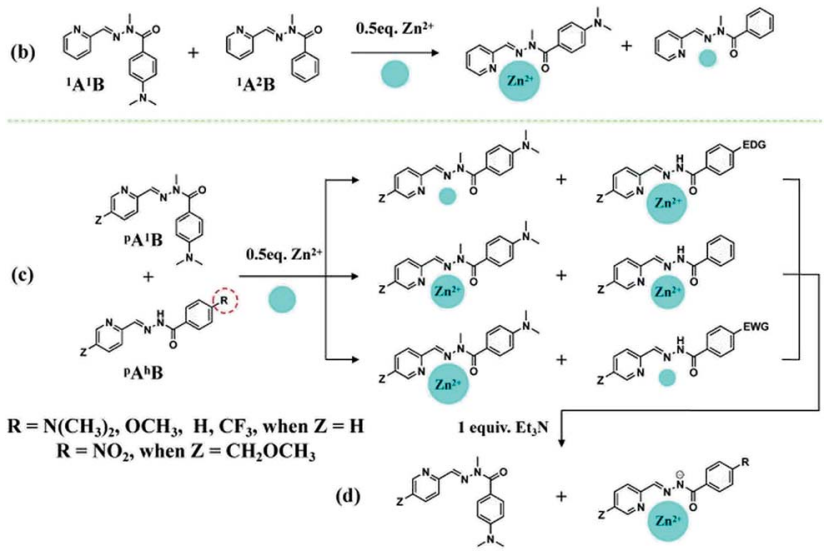

Scheme $2 \mathrm{Zn}^{2+}$ competition and transfer among PyAHs. (a) $\mathrm{Zn}^{2+}$ distribution in the mixture of 1 equiv. of ${ }^{1} A^{1} B$ and ${ }^{1} A^{3} B$ ( $3.5 \mathrm{mM}$ each) and 0.5 equiv. of $Z n^{2+}$. (b) $Z n^{2+}$ distribution in the mixture of 1 equiv. of ${ }^{1} A^{1} B$ and ${ }^{1} A^{2} B$ (3.5 mM each) and 0.5 equiv. of $Z^{2+}$. (c) $Z^{2+}$ distribution in the mixture of 1 equiv. of $\mathrm{N}$-methylated and $\mathrm{N}-\mathrm{H}$ PyAHs $\left({ }^{\mathrm{P}} \mathrm{A}^{1} \mathrm{~B}\right.$ and $\left.{ }^{\mathrm{b}} \mathrm{A}^{\mathrm{h}} \mathrm{B}\right)$ with different substituents on the $\mathrm{R}$ group of the hydrazide side ( $3.5 \mathrm{mM}$ each) and 0.5 equiv. of $\mathrm{Zn}^{2+}$. (c) $\mathrm{Zn}^{2+}$ distribution in the mixture of 1 equiv. of $\mathrm{N}$-methylated and $\mathrm{N}-\mathrm{H}$ PyAHs with different substituents on the $\mathrm{R}$ group of the hydrazide side $(3.5 \mathrm{mM}$ each); (d) 0.5 equiv. of $\mathrm{Zn}^{2+}$ and 1 equiv. of $\mathrm{Et}_{3} \mathrm{~N}$. The $\mathrm{CH}_{2} \mathrm{OCH}_{3}$ group was merely used to improve the solubility of $\mathrm{N}-\mathrm{H}$ PyAHs bearing a para $\mathrm{NO}_{2}$ group. In all cases, thermal equilibration was achieved by heating at $60^{\circ} \mathrm{C}$ for $6 \mathrm{~h}$. The size of the blue dots qualitatively indicates the relative amount of zinc complex within the pair of complexes formed in a given reaction. 
$\mathrm{OCH}_{3}$, for instance), and conversely, the $\mathrm{Zn}^{2+}$ ions were substantially captured by $N$-methylated PyAHs with respect to $\mathrm{N}-\mathrm{H}$ PyAHs with electron-withdrawing groups $\left(\mathrm{R}=\mathrm{CF}_{3}\right.$ or $\mathrm{NO}_{2}$, for instance).

According to our previous study, ${ }^{6}$ the deprotonation of $\mathrm{N}-\mathrm{H}$ PyAHs yields a monoanionic ligand capable of coordinating with a metal ion much more efficiently. Consequently, treating a 1/1 mixture of $N$-methylated and $\mathrm{N}-\mathrm{H}$ PyAHs (3.5 mM each) with half equiv. of $\mathrm{Zn}^{2+}$ in the presence of one equiv. of $\mathrm{Et}_{3} \mathrm{~N}$ displayed the almost exclusive formation of the monoanionic $\mathrm{Zn}^{\mathrm{II}}\left({ }^{\mathbf{P}} \mathbf{A}^{\mathbf{h}} \mathbf{B}^{-}\right)_{2}$ complex (close to $100 \%$ ) due to the transfer of $\mathrm{Zn}^{2+}$ to the ionized $\mathrm{N}^{-}$PyAHs, regardless of the electronic properties of the $\mathrm{R}$ group (Scheme $2 \mathrm{~d}$ ).

\section{Photoselection in CDLs of acylhydrazones}

3.1. Investigation of the photochemical behavior of acylhydrazones. Acylhydrazones have been proven to be widely tunable photoswitches ${ }^{6,13}$ based on $E / Z$ isomerization through photoinduced out-of-plane rotation about the $\mathrm{C}=\mathrm{N}$ bond and thermally activated in-plane nitrogen inversion, with their attractive features including facile preparation, high stability, efficiency of absorption, addressable and high fatigue resistance. ${ }^{\mathbf{1 3 a}}$

In this study, we independently investigated the spectroscopic properties under the irradiation of each constituent in the four aforementioned libraries as a function of structural variation. No clear change was found in the UV-vis in the acylhydrazones ${ }^{\mathbf{P}} \mathbf{A}^{\mathbf{1}} \mathbf{B}$ and ${ }^{\mathbf{b}} \mathbf{A}^{\mathbf{1}} \mathbf{B}\left({ }^{\mathbf{2}} \mathbf{A}^{\mathbf{1}} \mathbf{B},{ }^{\mathbf{3}} \mathbf{A}^{\mathbf{1}} \mathbf{B},{ }^{\mathbf{1}} \mathbf{A}^{\mathbf{1}} \mathbf{B}\right.$ and $\left.{ }^{\mathbf{4}} \mathbf{A}^{\mathbf{1}} \mathbf{B}\right)$ starting from their $E$-isomer in $\mathrm{CD}_{3} \mathrm{CN}(30 \mu \mathrm{M})$ under constant irradiation with a $125 \mathrm{~W}$ Hg-lamp in the $\lambda_{\text {irr }}=310-400 \mathrm{~nm}$ domain (see Fig. S17 $\dagger$ ), a change in $E$ to $Z$ conversion might be induced using the appropriate wavelength. The spectral properties of $E^{-}{ }^{\mathbf{b}} \mathbf{A}^{\mathbf{h}} \mathbf{B}$ $\left(E^{-}{ }^{3} \mathbf{A}^{\mathbf{8}} \mathbf{B}, E^{-}{ }^{\mathbf{4}} \mathbf{A}^{7} \mathbf{B}, E_{-}^{-4} \mathbf{A}^{5} \mathbf{B}\right.$ and $\left.E_{-}^{-4} \mathbf{A}^{\mathbf{3}} \mathbf{B}\right)$ derived from benzaldehyde ${ }^{\mathbf{b}} \mathbf{A}$ and non-methylated/N-H hydrazide ${ }^{\mathrm{h}} \mathrm{B}$ were then examined. $E^{-}{ }^{\mathbf{b}} \mathbf{A}^{\mathbf{h}} \mathbf{B}$ displayed an absorption band $\left(\lambda_{\max }\right)$ in the UV region from 284 to $330 \mathrm{~nm}$, showing a substantial bathochromic shift along with the electronic properties of the $\mathrm{R}$ group of the hydrazide moiety from the electron-withdrawing group $\mathrm{NO}_{2}$ to the electron-donating group $\mathrm{N}(\mathrm{Me})_{2}$ (Table $\mathrm{S} 5, \dagger$ the second column). Constant light irradiation $\left(\lambda_{\text {irr }}=310-400 \mathrm{~nm}\right)$ led to different decreases and hypsochromic shifts of $\lambda_{\max }$, indicating isomerization toward their $Z$-isomers (Fig. S18†). Clear isosbestic points suggested clean conversions from $E$ to $Z$-isomer upon irradiation. The thermodynamically less stable $Z$-isomers of ${ }^{\mathbf{b}} \mathbf{A}^{\mathbf{h}} \mathbf{B}$ returned to their $E$-isomers with relatively long half-lives of the $Z$-isomers at $25{ }^{\circ} \mathrm{C}$, which were also related to the electronic properties of the $\mathrm{R}$ group of the hydrazide part, increasing from $26 \mathrm{~min}$ for the $\mathrm{NO}_{2}$ group to $330 \mathrm{~min}$ for the $\mathrm{N}(\mathrm{Me})_{2}$ group. However, the half-lives of the $Z$ isomers of these acylhydrazones were dramatically reduced by the addition of $10 \% \mathrm{HCl}$ or $20 \% \mathrm{Sc}^{3+}$, which favor the conversion of $Z$ to $E$ and are also the catalysts for component exchange in the DCLS (Table S5, $\dagger$ the last two columns). In fact, the $Z-{ }^{\mathbf{b}} \mathbf{A}^{\mathbf{h}} \mathbf{B}$ isomers were not observed by ${ }^{1} \mathrm{H}$ NMR measurements even over a time usually larger than $10 \mathrm{~min}$. According to our previous studies, ${ }^{6,13 a}$ the non-methylated PyAHs ${ }^{\mathbf{p}} \mathbf{A}^{\mathbf{h}} \mathbf{B}\left({ }^{\mathbf{2}} \mathbf{A}^{\mathbf{8}} \mathbf{B},{ }^{\mathbf{1}} \mathbf{A}^{\mathbf{7}} \mathbf{B},{ }^{\mathbf{1}} \mathbf{A}^{\mathbf{6}} \mathbf{B},{ }^{\mathbf{1}} \mathbf{A}^{\mathbf{5}} \mathbf{B}\right.$,
${ }^{\mathbf{1}} \mathbf{A}^{\mathbf{4}} \mathbf{B}$ and ${ }^{1} \mathbf{A}^{\mathbf{3}} \mathbf{B}$ ), whose $Z$-isomers are stabilized by intramolecular H-bonding, are expected to be promising driving force candidates for amplifications in CDNs. In contrast to those of the $E^{-}{ }^{\mathbf{b}} \mathbf{A}^{\mathbf{h}} \mathbf{B}$, the $\lambda_{\max }$ values of the $E^{-}{ }^{\mathbf{p}} \mathbf{A}^{\mathbf{h}} \mathbf{B}$ were substantially independent of the R groups, except that of $E-{ }^{\mathbf{1}} \mathbf{A}^{\mathbf{3}} \mathbf{B}$ (335 nm, $\left.\mathrm{N}\left(\mathrm{CH}_{3}\right)_{2}\right)$ displaying a significant red shift relative to other $E_{-} \mathbf{P}^{\mathbf{P}} \mathbf{A}^{\mathbf{h}} \mathbf{B}$ compounds (Table $\mathbf{S} 6, \dagger$ the third column). Constant light irradiation resulted in decreases in absorption for $\lambda_{\max }$ and bathochromic shifts with clear isosbestic points (Fig. S19a-S24a $\dagger$ ). As expected, $Z-{ }^{\mathbf{P}} \mathbf{A}^{\mathbf{h}} \mathbf{B}$ showed high thermal stability regardless of the presence or absence of $10 \% \mathrm{HCl}$ or $20 \% \mathrm{Sc}^{3+}$ (Table S6, $\uparrow$ the last three columns).

3.2. Attempts of photoselection in DCLs of acylhydrazones. Based on the results above, we were interested in determining if there were any alterations of the CDNs NA to ND after the appropriate UV-lamp irradiation at room temperature. Unfortunately, such photoselection was unsuccessful for these four CDNs, and no significant variations in constituent distributions, starting from statistical distributions, were observed after $1 \mathrm{~h}$ of constant light irradiation with a wavelength range of $310-400 \mathrm{~nm}$, using either (1) $10 \% \mathrm{DCl}$ or (2) $20 \% \mathrm{Sc}^{3+}$ or (3) $10 \%$ DCl with $1 \% \mathrm{v} / \mathrm{v}$ aniline as catalysts (Scheme 3 , left). In the acidcatalyzed CDLs (10\% DCl or $10 \% \mathrm{DCl}$ with $1 \% \mathrm{v} / \mathrm{v}$ aniline), almost all distributions and ratios of $E / Z$ isomers of ${ }^{\mathbf{p}} \mathbf{A}^{\mathbf{h}} \mathbf{B}$ were preserved under exposure to light, except for ND with unchanged distribution but slight increase in the ratio of $E / Z$ isomers (Tables S1a-S4a†). With respect to CDNs with $20 \% \mathrm{Sc}^{3+}$, light irradiation resulted only in increases in the amounts of $Z$ isomer (larger enhancements for $\mathbf{N B}$ and NC, smaller enhancements for NA and ND), rather than in the constituent distributions (Tables S1b-S4b $\dagger$ ). The latter results indicated that it might be possible to enhance the photoconversion from $E$ to $Z$ isomers of ${ }^{\mathbf{P}} \mathbf{A}^{\mathbf{h}} \mathbf{B}$ under catalysis by $\mathrm{Sc}^{3+}$.

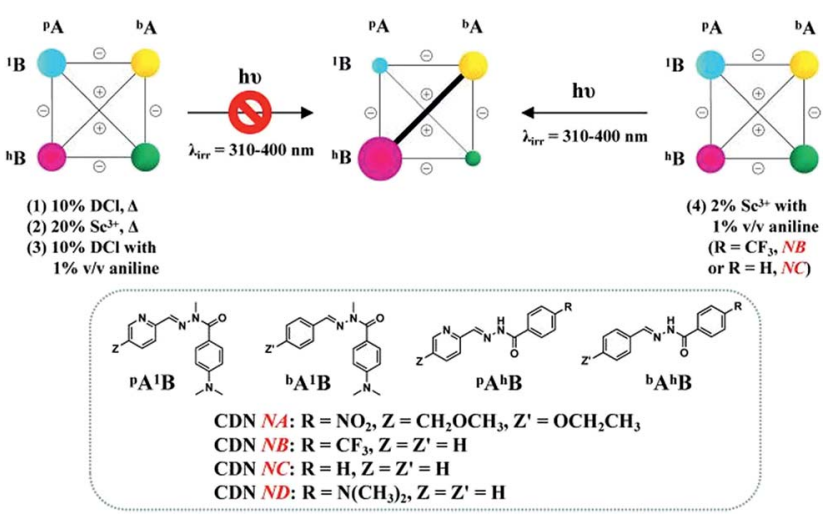

Scheme 3 Weighted graph representation of modifications of the four $[2 \times 2]$ CDNs of the four constituents ${ }^{\mathrm{P}} \mathrm{A}^{1} B,{ }^{\mathrm{b}} \mathrm{A}^{1} B,{ }^{\mathrm{P}} \mathrm{A}^{\mathrm{h}} B$ and ${ }^{\mathrm{b}} \mathrm{A}^{\mathrm{h}} \mathrm{B}$ (3.5 mM each) under light irradiation $\left(\lambda_{\text {irr }}=310-400 \mathrm{~nm}\right.$ ) starting from the statistical distribution in the presence of a different catalyst and temperature conditions. (Top left) No photoselection takes place with catalysts (1)-(3). (Top right) the system undergoes photoselection in the case of NB and NC in the presence of the combined catalysts (4). ${ }^{\mathrm{P}} \mathrm{A}^{\mathrm{h}} \mathrm{B}$ exists in both $E$ and $Z$ isomers. The diagonal and edges of the square link agonistic (+) and antagonistic (-) constituents, respectively. See Tables S1-S4† for numerical values. 
In order to unravel the reason for such $\mathrm{Sc}^{3+}$-induced enhancements of the photo-conversion from $E$ to $Z$ isomers, the $Z$-isomer ratios following the photo-isomerization from $E$ to $Z$ isomers of $\mathrm{N}-\mathrm{H}$ PyAHs ${ }^{\mathbf{P}} \mathbf{A}^{\mathbf{h}} \mathbf{B}\left({ }^{2} \mathbf{A}^{\mathbf{8}} \mathbf{B},{ }^{\mathbf{1}} \mathbf{A}^{\mathbf{7}} \mathbf{B},{ }^{\mathbf{1}} \mathbf{A}^{\mathbf{6}} \mathbf{B},{ }^{\mathbf{1}} \mathbf{A}^{\mathbf{5}} \mathbf{B},{ }^{\mathbf{1}} \mathbf{A}^{\mathbf{4}} \mathbf{B}\right.$ and $\left.{ }^{\mathbf{1}} \mathbf{A}^{\mathbf{3}} \mathbf{B}\right)$ under constant light irradiation $\left(\lambda_{\text {irr }}=310-400 \mathrm{~nm}\right)$ were then studied as a function of time, whereby quantitative evaluation of their photostationary states were determined by ${ }^{1} \mathrm{H}$ NMR measurements (Fig. S25 $\dagger$ ). We found that except for ${ }^{\mathbf{1}} \mathbf{A}^{\mathbf{3}} \mathbf{B}$ with $\mathrm{R}=\mathrm{N}\left(\mathrm{CH}_{3}\right)_{2}$, all the $\mathrm{N}-\mathrm{H}$ PyAHs displayed relatively low conversion ( $\leq 51 \%$ ) from $E$ to $Z$ under sufficient duration $(>150$ min) of irradiation (Scheme $S 9, \uparrow$ top). The reason may be that under light irradiation with a given range of wavelengths from 310 to $400 \mathrm{~nm},{ }^{\mathbf{1}} \mathbf{A}^{\mathbf{3}} \mathbf{B}$ with a maximum absorption band at $335 \mathrm{~nm}$ may have the strongest absorption compared to the other ${ }^{\mathbf{P}^{\mathbf{h}} \mathbf{B}}$ ( $\lambda_{\max }$ around $\left.300 \mathrm{~nm}\right)$. Surprisingly, in the presence of a catalytic amount of $2 \% \mathrm{Sc}^{3+}$ (Fig. S26 and Scheme S9, $\uparrow$ bottom), long time ( $>300 \mathrm{~min}$ ) light irradiation led to larger conversion ( $\geq 79 \%$ ) for almost all cases except that for ${ }^{2} \mathbf{A}^{\mathbf{8}} \mathbf{B}$ with $\mathrm{R}=\mathrm{NO}_{2}$ (one possible explanation is due to the weak interaction between $\mathrm{Sc}^{3+}$ and $\left.{ }^{2} \mathbf{A}^{\mathbf{8}} \mathbf{B}\right)$. By comparing the ratio of $Z$-isomers in the absence and presence of $\mathrm{Sc}^{3+}$, enhancements of the $Z$-isomer ratios with different $\mathrm{R}$ groups in the presence of $\mathrm{Sc}^{\mathrm{III}}(\mathrm{OTf})_{3}$ under sufficient duration of constant light irradiation $\left(\lambda_{\text {irr }}=310-400 \mathrm{~nm}\right)$ are demonstrated in Fig. S27. $\dagger$ Large enhancements were found in the photoisomerization of PyAHs with $\mathrm{R}=\mathrm{CF}_{3}, \mathrm{Cl}, \mathrm{H}$ and $\mathrm{OCH}_{3}$, with unsuccessful catalysis in the case when $\mathrm{R}=\mathrm{NO}_{2}$ or $\mathrm{R}=\mathrm{N}\left(\mathrm{CH}_{3}\right)_{2}$. The reason for these enhancements may be attributed to the increase in light absorption caused by the $\mathrm{Sc}^{3+}$-induced red shift of the absorption bands $\lambda_{\max }$, extending into the irradiation range of 310$400 \mathrm{~nm}$ (See Table S6 and Fig. S19b-S24b $\dagger$ ).

3.3. Successful photoselection in DCLs of acylhydrazones. Taking together the results above, $\mathrm{Sc}^{3+}$ appears to be a promising agent for achieving photoselection within the DCLs of acylhydrazones through a dual effect: (i) catalyzing component exchange at room temperature in the presence of aniline, by facilitating hydrolysis, condensation and exchange reactions at the $\mathrm{C}=\mathrm{N}$ bond ${ }^{\mathbf{1 4}^{4}}$ (ii) increasing the $E$ to $Z$ conversion of PyAHs under irradiation by increasing light absorption. Indeed, by using the catalyst pair of $2 \% \mathrm{Sc}^{3+}$ and $1 \% \mathrm{v} / \mathrm{v}$ aniline and inducing $E$ to $Z$ photoisomerization, photoselection was successfully achieved for the CDNs NB and NC in response to constant light irradiation leading to the amplification of a single diagonal of the network (Scheme 3, top right). The results for the photoselection of these CDNs are described in more detail below.

\section{Triple adaptation in CDNs based on four acylhydrazone CDLs}

On the basis of the results above, four DCLs, each with four constituents, were subjected to the application of triple external perturbations: metalloselection, base-metalloselection and photoselection. The following results (A)-(D) were obtained.

(A) First, we investigated the multiple adaptations of the DCL formed by constituents ${ }^{\mathbf{2}} \mathbf{A}^{\mathbf{1}} \mathbf{B},{ }^{3} \mathbf{A}^{\mathbf{1}} \mathbf{B},{ }^{2} \mathbf{A}^{\mathbf{8}} \mathbf{B}$ and ${ }^{3} \mathbf{A}^{\mathbf{8}} \mathbf{B}\left(\mathrm{R}=\mathrm{NO}_{2}\right)$ starting from its statistical distribution within the CDN NA.
(A-1) Metalloselection: this initial mixture of four constituents $\left({ }^{2} \mathbf{A}^{\mathbf{1}} \mathbf{B},{ }^{3} \mathbf{A}^{\mathbf{1}} \mathbf{B}, E / Z^{-}{ }^{2} \mathbf{A}^{\mathbf{8}} \mathbf{B}\right.$ and ${ }^{3} \mathbf{A}^{\mathbf{8}} \mathbf{B}, 3.5 \mathrm{mM}$ each) was treated with 0.5 eq. of $\mathrm{Zn}^{2+}$ (with respect to the amount of components, $3.5 \mathrm{mM}$ ) under equilibration by heating at $60{ }^{\circ} \mathrm{C}$ for $10 \mathrm{~h}$ either with or without the addition of catalysts $\left(10 \% \mathrm{DCl}\right.$ or $\left.20 \% \mathrm{Sc}^{3+}\right)$. The zinc ions were distributed between ${ }^{\mathbf{2}} \mathbf{A}^{\mathbf{1}} \mathbf{B}$ and ${ }^{2} \mathbf{A}^{\mathbf{8}} \mathbf{B}$, with $67 \%$ (of total $\mathrm{Zn}^{2+}$ ) binding to the former constituent and $33 \%$ binding to the latter (NA-Zn in Table S7, $\uparrow$ middle center), which is in accordance with the discussion above (Scheme S8 $\dagger^{\dagger}$ ). Such a marked bias in the $\mathrm{Zn}^{2+}$ capture between the two PyAHs led to the reorganization of the DCL to amplify the constituent ${ }^{2} \mathbf{A}^{\mathbf{1}} \mathbf{B}$, presenting the strongest $\mathrm{Zn}^{2+}$ binding, in the form of its octahedral complex $\mathrm{Zn}^{\mathrm{II}}\left({ }^{\mathbf{2}} \mathbf{A}^{\mathbf{1}} \mathbf{B}\right)_{2}$, the mixed ligand complex $\mathrm{Zn}^{\mathrm{II}}\left({ }^{\mathbf{2}} \mathbf{A}^{\mathbf{1}} \mathbf{B}\right.$, $\left.{ }^{2} \mathbf{A}^{\mathbf{8}} \mathbf{B}\right)$ together with $E^{-2} \mathbf{A}^{\mathbf{1}} \mathbf{B}$, as well as simultaneously its diagonally linked agonist ${ }^{3} \mathbf{A}^{\mathbf{8}} \mathbf{B}$ (agonist amplification). The resulting modified network NA-Zn presented the distribution $32 \% / 16 \% /$ $18 \% / 32 \%$ for the constituents ${ }^{2} \mathbf{A}^{\mathbf{1}} \mathbf{B} /{ }^{3} \mathbf{A}^{\mathbf{1}} \mathbf{B} /{ }^{2} \mathbf{A}^{\mathbf{8}} \mathbf{B} /{ }^{3} \mathbf{A}^{8} \mathbf{B}$, respectively, with $2 \%$ hydrolysis (Scheme 4 , middle center).

(A-2) Base-metalloselection: the base-induced deprotonation of constituent ${ }^{2} \mathbf{A}^{\mathbf{8}} \mathbf{B}$ is expected to dramatically enhance its affinity toward zinc ions; therefore, treating the same DCL with 0.5 eq. $\mathrm{Zn}^{2+}$ and 1eq. $\mathrm{Et}_{3} \mathrm{~N}$ caused a rearrangement of the CDN $\mathbf{N A}$ to the almost exclusive formation of the $\mathrm{Zn}^{\mathrm{II}}\left({ }^{2} \mathbf{A}^{\mathbf{8}} \mathbf{B}^{-}\right)_{2}$ complex ( $\mathbf{N A - Z n E t} \mathbf{Z}_{3} \mathbf{N}$ in Table $\mathbf{S} 7, \dagger$ middle left). This acted as a driving force for the modification of the network from the initial statistical uniformity to the diagonal amplification of ${ }^{2} \mathbf{A}^{\mathbf{8}} \mathbf{B}$ and its agonist ${ }^{\mathbf{3}} \mathbf{A}^{\mathbf{1}} \mathbf{B}$, a distribution orthogonal to the metalloselection distribution (NA-Zn). The resulting distribution was $16 \% / 34 \% / 33 \% / 11 \%$ for the ${ }^{2} \mathbf{A}^{\mathbf{1}} \mathbf{B} /{ }^{3} \mathbf{A}^{\mathbf{1}} \mathbf{B} /{ }^{2} \mathbf{A}^{\mathbf{8}} \mathbf{B} /{ }^{\mathbf{3}} \mathbf{A}^{\mathbf{8}} \mathbf{B}$, constituents respectively, with $5 \%$ hydrolysis. These results showed that NA can undergo dual orthogonal adaptation.

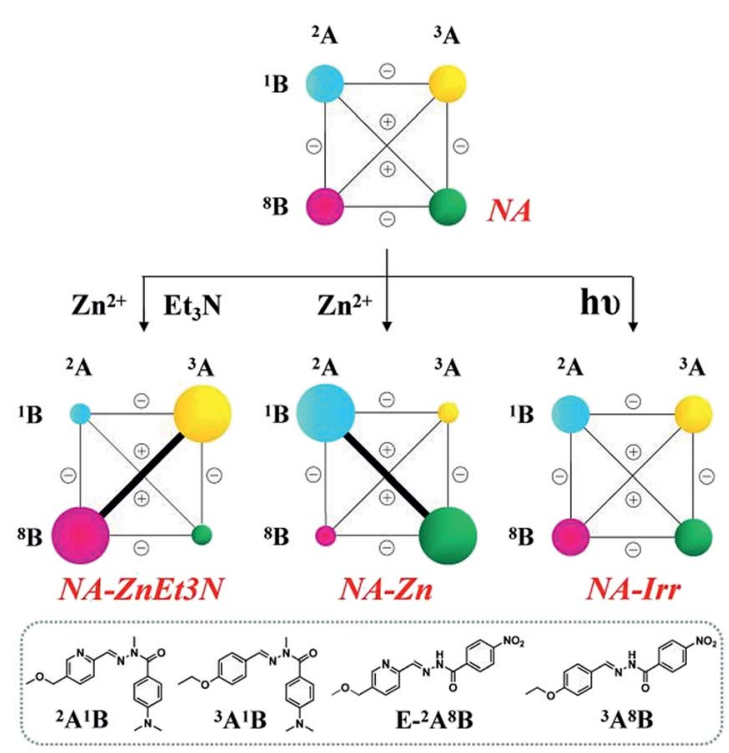

Scheme 4 Weighted graph representation of triple adaptation within the $[2 \times 2]$ CDN NA from the statistical distribution (top) of the four constituents ${ }^{2} A^{1} B,{ }^{3} A^{1} B,{ }^{2} A^{8} B$ and ${ }^{3} A^{8} B(3.5 \mathrm{mM}$ each) in response to 0.5 eq. $\mathrm{Zn}^{2+} \& 1$ eq. $\mathrm{Et}_{3} \mathrm{~N}$ (middle left), 0.5 eq. $\mathrm{Zn}^{2+}$ (middle center) and light irradiation $\left(\lambda_{\text {irr }}=310-400 \mathrm{~nm}\right.$, middle right) ${ }^{a}$. ${ }^{a}$ See text and ESI for conditions, catalyst and temperature. See Table $\mathrm{S} 7 \uparrow$ for numerical values. 
(A-3) Photoselection attempt: the same four-membered network underwent light irradiation $(310-400 \mathrm{~nm})$ in the presence of the catalysts, $2 \% \mathrm{Sc}^{3+}$ and $1 \% \mathrm{v} / \mathrm{v}$ aniline in order to increase the isomerization conversion from the $E$ to $Z$ isomer and activate the component exchange reaction of the system. The latter did not take place and the stated statistical distribution remained unchanged (NA-Irr in Scheme 4, middle right), albeit limited enhancement of the $Z$-isomer from $11 \%$ to $12 \%$ was observed after light irradiation (NA-Irr in Table S7, middle right; Table S1c†).

It is worth noting that each perturbation (basemetalloselection, metalloselection and photoselection) induces a specific distribution of the four dynamic constituents, allowing, in principle, for the identification of the perturbing agent that gives rise to it.

(B) Under the action of the same perturbation agents, base, metal ion and light, the DCL consisting of the four constituents ${ }^{\mathbf{1}} \mathbf{A}^{\mathbf{1}} \mathbf{B},{ }^{\mathbf{4}} \mathbf{A}^{\mathbf{1}} \mathbf{B},{ }^{\mathbf{1}} \mathbf{A}^{\mathbf{7}} \mathbf{B}$ and ${ }^{\mathbf{4}} \mathbf{A}^{\mathbf{7}} \mathbf{B}$ exhibited triple adaptation, expressing different biased distributions within network $\mathbf{N B}\left(\mathrm{R}=\mathrm{CF}_{3}\right)$ compared to network NA.

(B-1) Metalloselection: on addition of 0.5 eq. $\mathrm{Zn}^{2+}(3.5 \mathrm{mM})$ to this DCL with the initial statistical distribution, the difference in the zinc ion affinities between ${ }^{\mathbf{1}} \mathbf{A}^{\mathbf{1}} \mathbf{B}$ and ${ }^{\mathbf{1}} \mathbf{A}^{\mathbf{7}} \mathbf{B}$ resulted in a marked metalloselection by $61 \%$ of $\mathrm{Zn}$ capture for ${ }^{\mathbf{1}} \mathrm{A}^{\mathbf{1}} \mathbf{B}$ with respect to $39 \%$ for ${ }^{\mathbf{1}} \mathbf{A}^{\mathbf{7}} \mathbf{B}$; the decreased ability for zinc ion binding is attributed to its electron-withdrawing $\mathrm{CF}_{3}$ group (NB$\mathbf{Z n}$ in Table S8, $\uparrow$ middle center). As a result, DCL recombination resulted in the pronounced amplification of the former ligand ${ }^{1} \mathbf{A}^{\mathbf{1}} \mathbf{B}$ at the expense of its antagonist constituents containing either ${ }^{\mathbf{1}} \mathbf{A}$ or ${ }^{\mathbf{1}} \mathbf{B}$ and consequently a corresponding up-regulation of its agonist ${ }^{4} \mathbf{A}^{7} \mathbf{B}$ (NB-Zn in Scheme 5 , middle center).

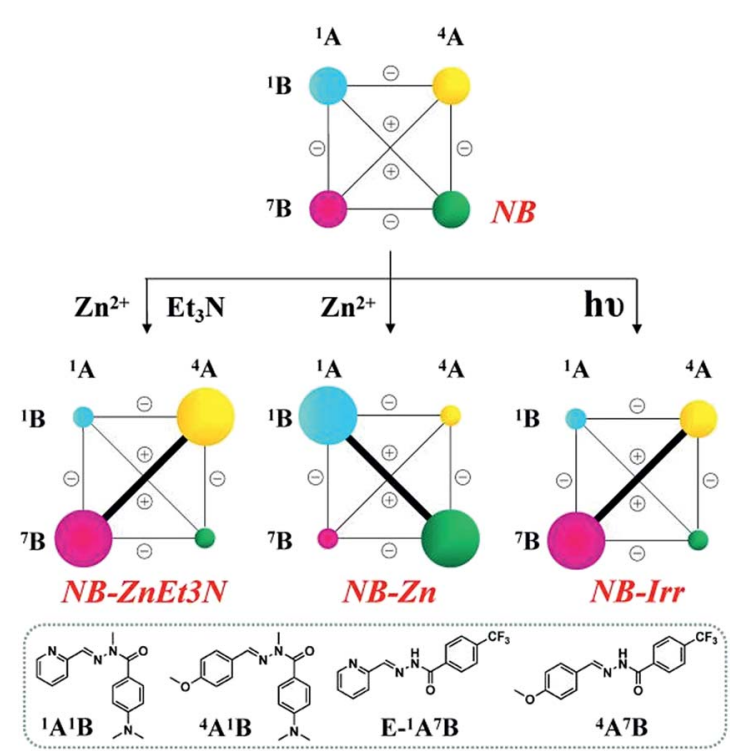

Scheme 5 Weighted graph representation of the triple adaptation of the [ $2 \times 2$ ] CDN NB from the statistical distribution (top) of the four constituents ${ }^{1} A^{1} B,{ }^{4} A^{1} B,{ }^{1} A^{7} B$ and ${ }^{4} A^{7} B$ (3.5 mM each) in response to 0.5 eq. $\mathrm{Zn}^{2+} \& 1$ eq. $\mathrm{Et}_{3} \mathrm{~N}$ (middle left), 0.5 eq. $\mathrm{Zn}^{2+}$ (middle center) and light irradiation $\left(\lambda_{\text {irr }}=310-400 \mathrm{~nm}\right.$, middle right) ${ }^{a}$. ${ }^{a}$ See text and ESI for conditions, catalyst and temperature. See Table S8† for numerical values.
(B-2) Base-metalloselection: as expected, in the presence of $3.5 \mathrm{mM} \mathrm{Zn}{ }^{2+}$ (0.5 eq. with respect to the concentration of components) and $7 \mathrm{mM} \mathrm{Et}_{3} \mathrm{~N}$ (1 eq.), constituent ${ }^{\mathbf{1}} \mathbf{A}^{7} \mathbf{B}$ underwent strong up-regulation on deprotonation of its $\mathrm{N}-\mathrm{H}$ site with concomitant amplification of its agonist ${ }^{\mathbf{4}} \mathbf{A}^{\mathbf{1}} \mathbf{B}\left(\mathbf{N B}^{-} \mathbf{Z n E t} \mathbf{t}_{3} \mathbf{N}\right.$ in Scheme 5 , middle left). This reorganization process of the DCL was kinetically slow and required acceleration using catalysts ( $1 \% \mathrm{v} / \mathrm{v}$ aniline, for instance).

(B-3) Photoselection: light irradiation (310-400 $\mathrm{nm}$ ) promoted the $E$ to $Z$ photoisomerization of PyAHs ${ }^{\mathbf{1}} \mathbf{A}^{\mathbf{7}} \mathbf{B}$ with the assistance of $\mathrm{N}-\mathrm{H} \cdots \mathrm{N}$ hydrogen bonding and in the presence of $2 \% \mathrm{Sc}^{3+}$ ions from an initial $Z$-isomer ratio of $7 \%$ to $25 \%$ (see Tables S2c and S8†). When the irradiation of the DCL was conducted in the presence of both $2 \% \mathrm{Sc}^{3+}$ and $1 \% \mathrm{v} / \mathrm{v}$ aniline to catalyze component exchange, the composition of the library was modified giving a distribution of $19 \% / 20 \% / 30 \% / 18 \%$ for constituents ${ }^{\mathbf{1}} \mathbf{A}^{\mathbf{1}} \mathbf{B} /{ }^{\mathbf{4}} \mathbf{A}^{\mathbf{1}} \mathbf{B} /{ }^{\mathbf{1}} \mathbf{A}^{\mathbf{7}} \mathbf{B} /{ }^{4} \mathbf{A}^{7} \mathbf{B}$, respectively, together with $13 \%$ hydrolysis (NB-Irr in Table S8, $\uparrow$ middle right). The corresponding rearranged $\mathrm{CDN}$ thus showed a simultaneous diagonal amplification of constituent ${ }^{\mathbf{1}} \mathbf{A}^{\mathbf{7}} \mathbf{B}$ and of its agonist ${ }^{\mathbf{4}} \mathbf{A}^{\mathbf{1}} \mathbf{B}$ (NB-Irr in Scheme 5, middle right).

Remarkably, one may note that this CDN undergoes orthogonal dual adaptation in response to two orthogonal external agents: a chemical effector, $\mathrm{Zn}^{2+}$, and a physical stimulus, light irradiation.

(C) We then investigated the multiple adaptations of the DCL containing the four interconvertible constituents ${ }^{\mathbf{1}} \mathbf{A}^{\mathbf{1}} \mathbf{B},{ }^{\mathbf{4}} \mathbf{A}^{\mathbf{1}} \mathbf{B}$, ${ }^{1} \mathbf{A}^{5} \mathbf{B}$ and ${ }^{4} \mathbf{A}^{\mathbf{5}} \mathbf{B}(\mathrm{R}=\mathrm{H})$ within the network NC.

(C-1) Metalloselection attempt: in view of the lack of preference for zinc ions between ${ }^{\mathbf{1}} \mathbf{A}^{\mathbf{1}} \mathbf{B}$ and ${ }^{\mathbf{1}} \mathbf{A}^{\mathbf{5}} \mathbf{B}$ as discussed above, applying $\mathrm{Zn}^{2+}$ to the evenly distributed CDN NC did not change the distribution pattern of the network (NC-Zn in Scheme 6, middle center).

(C-2) Base-metalloselection: as expected, the constitutional distribution of this DCL underwent a similar diagonal amplification of the agonist constituents ${ }^{\mathbf{1}} \mathbf{A}^{\mathbf{5}} \mathbf{B}$ and ${ }^{\mathbf{4}} \mathbf{A}^{\mathbf{1}} \mathbf{B}\left(\mathbf{N C}-\mathbf{Z n E t}_{3} \mathbf{N}\right.$ in Scheme 6, middle left; see Table $\mathrm{S} 9 \dagger$ for numerical values) as observed above for the CDNs NA and NB.

(C-3) Photoselection: according to the results shown in Fig. S27 and Table S9, $\dagger$ irradiation of the above library in the presence of $2 \% \mathrm{Sc}^{3+}$ enhanced the $E$ to $Z$ conversion of ${ }^{\mathbf{1}} \mathbf{A}^{\mathbf{5}} \mathbf{B}$ from $11 \%$ to $30 \%$ (percentages of the $Z$-isomers). As in the case of network NB after $1 \mathrm{~h}$ of constant irradiation $(310-400 \mathrm{~nm})$, the percentage of the constituents of the diagonal ${ }^{\mathbf{1}} \mathbf{A}^{\mathbf{5}} \mathbf{B}-{ }^{\mathbf{4}} \mathbf{A}^{\mathbf{1}} \mathbf{B}$ underwent up-regulation relative to the other diagonal ${ }^{\mathbf{1}} \mathbf{A}^{\mathbf{1}} \mathbf{B}$ ${ }^{4} \mathbf{A}^{5} \mathbf{B}$, although there was no amplification of ${ }^{\mathbf{4}} \mathbf{A}^{\mathbf{1}} \mathbf{B}$ with respect to the starting network (from $25 \%$ to $24 \%$, see Table S9†) due to the light-induced hydrolysis. The result is a markedly biased distribution of $16 \% / 24 \% / 34 \% / 18 \%$ for the constituents ${ }^{1} \mathbf{A}^{1} \mathbf{B} /{ }^{4} \mathbf{A}^{1} \mathbf{B} /{ }^{1} \mathbf{A}^{5} \mathbf{B} /{ }^{\mathbf{4}} \mathbf{A}^{5} \mathbf{B}$, respectively, together with around $7 \%$ hydrolysis (NC-Irr in Table S9, $\dagger$ middle right).

(D) Finally, the fourth DCL containing equimolar amounts of constituents ${ }^{\mathbf{1}} \mathbf{A}^{\mathbf{1}} \mathbf{B},{ }^{\mathbf{4}} \mathbf{A}^{\mathbf{1}} \mathbf{B},{ }^{\mathbf{1}} \mathbf{A}^{3} \mathbf{B}$ and ${ }^{\mathbf{4}} \mathbf{A}^{\mathbf{3}} \mathbf{B}$ was similarly subjected to the application of the three agents, metal ions, base and light within the CDN ND.

(D-1) Metalloselection: according to the data above, the added $\mathrm{Zn}^{2+}$ ions are expected to be selectively captured by PyAH 

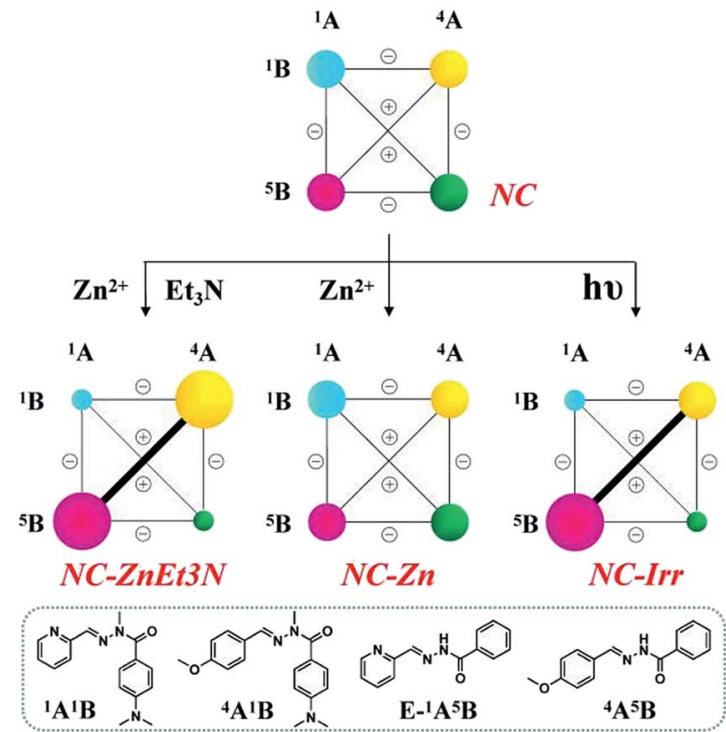

Scheme 6 Weighted graph representation of triple adaptation within the $[2 \times 2$ ] $C D N ~ N C$ from the statistical distribution (top) of the four constituents ${ }^{1} A^{1} B,{ }^{4} A^{1} B,{ }^{1} A^{5} B$ and ${ }^{4} A^{5} B$ (3.5 mM each) in response to 0.5 eq. $\mathrm{Zn}^{2+}$ and 1 eq. Et ${ }_{3} \mathrm{~N}$ (middle left), 0.5 eq. $\mathrm{Zn}^{2+}$ (middle center) and light irradiation $\left(\lambda_{\text {irr }}=310-400 \mathrm{~nm}\right.$, middle right ${ }^{a}{ }^{a}$ See text and ESI for conditions, catalyst and temperature. See Table $\mathrm{S} 9 \dagger$ for numerical values.

${ }^{\mathbf{1}} \mathbf{A}^{\mathbf{3}} \mathbf{B}$ in preference to other constituents in this DCL, as it presents both a favorable $\mathrm{N}-\mathrm{H}$ site and a strongly electrondonating $\mathrm{N}(\mathrm{Me})_{2}$ group that increases electron density on the carbonyl group. Such metalloselection yields a distribution of $17 \% / 32 \% / 33 \% / 15 \%$ for the constituents ${ }^{\mathbf{1}} \mathbf{A}^{\mathbf{1}} \mathbf{B} /{ }^{4} \mathbf{A}^{\mathbf{1}} \mathbf{B} /{ }^{1} \mathbf{A}^{3} \mathbf{B} /{ }^{4} \mathbf{A}^{3} \mathbf{B}$, respectively, together with $3 \%$ hydrolysis (ND-Zn in Table S10, $\dagger$ middle center), displaying a diagonal amplification in the network (ND-Zn in Scheme 7, middle center), unlike the behavior of the former cases NA-Zn, NB-Zn and NC-Zn.

(D-2) Base-metalloselection: the synergistic perturbation of the same DCL by $\mathrm{Zn}^{2+}$ and $\mathrm{Et}_{3} \mathrm{~N}$ together gave the same distribution bias as observed on application of these agents to the

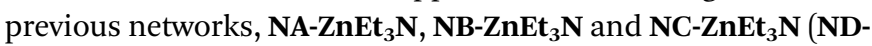
$\mathbf{Z n E t}_{3} \mathbf{N}$ in Scheme 7, middle left).

(D-3) Photoselection attempt: on exposure to constant light irradiation $\left(\lambda_{\text {irr }}=310-400 \mathrm{~nm}\right.$, for $\left.1 \mathrm{~h}\right)$, the photoresponsive constituent ${ }^{\mathbf{1}} \mathbf{A}^{\mathbf{3}} \mathbf{B}$ underwent only a small increase in isomerization with enhancement of the $Z$-isomer ratio from $12 \%$ to $17 \%$, whereas the statistical distribution of the constituents of the DCL remained unchanged.

\section{Information processing in CDNs with triple inputs and ternary outputs}

The four DCLs above adapt/respond to the application of the three agents, base-metalloselection, metalloselection and photoselection, by generating/expressing a constitutional state, characteristic of a given DCL/agent pair, represented by specific distributions of the constituents within the corresponding square CDN through the agonistic/antagonistic relationships between the constituents. The triple input perturbations (metal

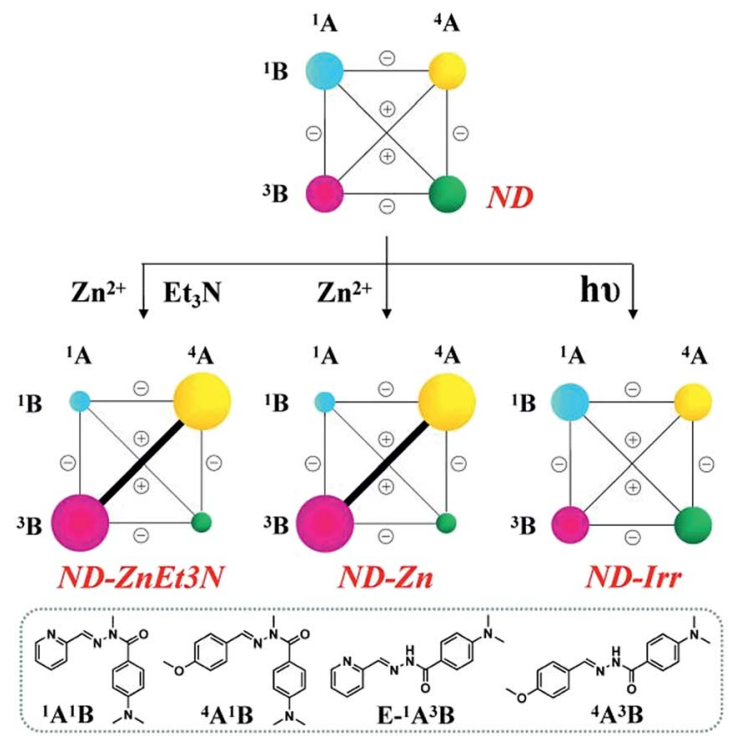

Scheme 7 Weighted graph representation of triple adaptation within the $[2 \times 2$ ] CDN ND from the statistical distribution (top) of the four constituents ${ }^{1} A^{1} B,{ }^{4} A^{1} B,{ }^{1} A^{3} B$ and ${ }^{4} A^{3} B$ (3.5 mM each) in response to 0.5 eq. $\mathrm{Zn}^{2+}$ and 1 eq. Et ${ }_{3} \mathrm{~N}$ (middle left), 0.5 eq. $\mathrm{Zn}^{2+}$ (middle center) and light irradiation $\left(\lambda_{\text {irr }}=310-400 \mathrm{~nm} \text {, middle right }\right)^{a}$. ${ }^{a}$ See text and ESI for conditions, catalyst and temperature. See Table S10 $\dagger$ for numerical values.

ion, base and light) enforce different constitutional states that define the response to a given agent and provide a readout that is characteristic of a given DCL. The present set of four

Table 1 The three different inputs (vertical) produce four different readouts (horizontal) characterizing the four different DCLs and their CDNs NA-ND and corresponding to the effect of these agents on them. In [2 $\times 2$ ] networks, the outputs possess three states $(-1,0$ and 1) related to three different types of constitutional distributions: a statistical one $(0)$ and two orthogonally amplified ones $(1,-1)$. The four [ $2 \times 2$ ] DCLs NA-ND of acylhydrazones respond to the triple inputs, base-metalloselection, metalloselection and photoselection, as described above

BASE-

METALLO METALLO PHOTO

SELECTION SELECTION SELECTION

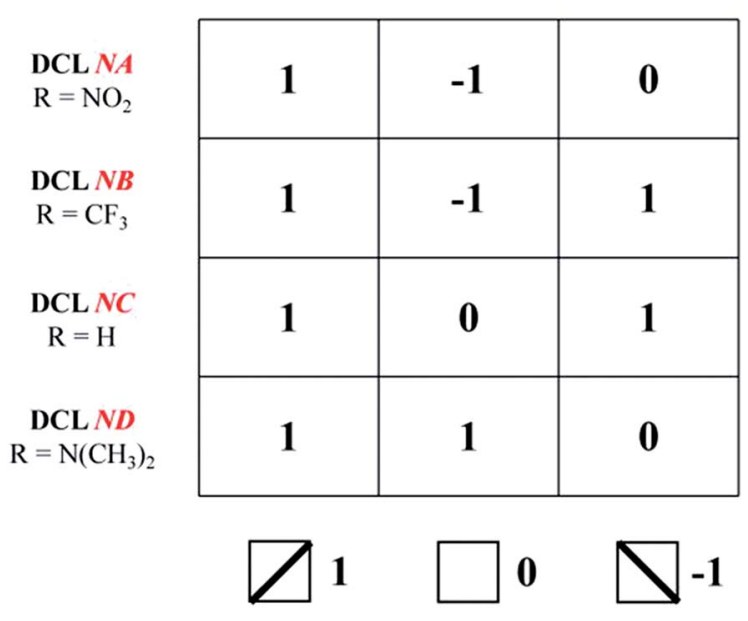


acylhydrazone-based CDNs may thus be developed as information devices based on the storage of information in a distributional pattern. As shown in Table 1, a given input agent yields a specific output represented by $-1,0$ and 1 for statistical distribution (0) and expression of a network diagonal ( -1 and 1). The ternary outputs generated by the three perturbations encode a specific horizontal readout defining each of the DCLs/ CDNs investigated. As indicated in Table 1, the four DCLs NAND are specifically encoded into the horizontal readouts $(1,-1$, $0),(1,-1,1),(1,0,1)$ and $(1,1,0)$, respectively, under the action of the three inputs. On the other hand, the vertical readouts $(1$, $1,1,1),(-1,-1,0,1)$ and $(0,1,1,0)$ for the four DCLs, respectively, are characteristic of the applied input agent, basemetalloselection, metalloselection and photoselection, respectively. Thus, Table 1 characterizes both a given DCL (horizontal; line) and a specific perturbing agent (vertical; column) in an informational double entry CDN matrix.

\section{Experimental}

For experimental details, see the ESI. $\dagger$

\section{Conclusions}

The present study of four acylhydrazones-based DCLs, represented by the corresponding CDNs, has achieved three goals: (1) the successful switching of the CDN NB between two orthogonal distributions under metallo- and photo-selection, respectively; (2) the expression of specific CDN distributions in DCLs subjected to three different agents, metal cation, base + metal cation and light irradiation, acting on four different CDLs; (3) the storage of molecular information in dynamic distributions that link triple inputs with ternary outputs (Table 1).

The latter deserves some further elaboration. It confirms the interest of such constitutional dynamic systems for exploring the storage and processing of molecular information not through specific molecular recognition processes between complementary components but through distributions of constituents in dynamic interconnection in a network. The network explored here is the simplest one involving four constituents located at the vertexes of a square and connected by agonistic (diagonals) and antagonistic (edges) relationships. This may in principle be extended to networks of higher complexity, such as the reported $[3 \times 3]^{3 k}$ and $3 \mathrm{D}$ networks. ${ }^{15}$

In general terms, the perturbation of a DCL by a given chemical or physical agent induces a redistribution of all linked constituents in the CDN that will result in a specific distribution corresponding to a given output code (such as those displayed in Table 1 for the present study), which may be considered as a sort of fingerprint, a constitutional engram ${ }^{2 b, 2 d}$ of dynamic nature, characteristic of that perturbation. Such storage of chemical information in dynamic constitutional distributions has been described for the effect of different alkali metal cations on a library of dynamic covalent polymers. ${ }^{16}$ On the other hand, the response of a given CDN to the application of multiple chemical/physical agents generates a specific combination of distributional outputs. Such processes establish a two-way link between a driving agent and a set of outputs in an informational double entry CDN matrix. Of course, the features of DCLs hold as well for non-covalent constituents, i.e. altogether for constitutional dynamic libraries operating on the covalent molecular, and the non-covalent supramolecular levels. ${ }^{2,3}$

\section{Conflicts of interest}

There are no conflicts to declare.

\section{Acknowledgements}

The authors thank the ERC (Advanced Research Grant SUPRADAPT 290585), the ANR Grant DYNAFUN and the University of Strasbourg Institute for Advanced Study (USIAS) for financial support. GWM gratefully acknowledges Professor Shimei Jiang (Jilin University, Changchun), Dr Ghislaine Vantomme and Dr Martin Herder for extensive discussions, as well as the National Natural Science Foundation of China (51673082) and the above ERC grant for post-doctoral fellowship support.

\section{Notes and references}

1 For complexity and complex systems, see, for instance:( $a$ ) K. Mainzer, Thinking in Complexity, Springer, Berlin, 5th edn, 2007; (b) R. Cohen and S. Havlin, Complex Networks, Cambridge University Press, Cambridge, 2010; (c) G. Nicolis and C. Nicolis, Foundations of Complex Systems, World Scientific Publishing Co., Singapore, 2nd edn, 2012; (d) J.-M. Lehn, Angew. Chem., Int. Ed., 2013, 52, 2836-2850; (e) I. Alfonso, Chem. Commun., 2016, 52, 239-250.

2 For a selection of papers on constitutional dynamic chemistry, see, for instance:(a) J.-M. Lehn, Proc. Natl. Acad. Sci. U. S. A., 2002, 99, 4763-4768; (b) J.-M. Lehn, Chem. Soc. Rev., 2007, 36, 151-160; (c) Constitutional Dynamic Chemistry: Topics in Current Chemistry, ed. M. Barboiu, Springer, 2012, vol. 322; (d) J.-M. Lehn, Angew. Chem., Int. Ed., 2015, 54, 3276-3289.

3 For recent examples of constitutional dynamic networks, see, for instance:(a) N. Giuseppone and J.-M. Lehn, Chem.Eur. J., 2006, 12, 1715-1722; (b) S. Ulrich and J.-M. Lehn, Chem.-Eur. J., 2009, 15, 5640-5645; (c) L. Lao, J.-L. Schmitt and J.-M. Lehn, Chem.-Eur. J., 2010, 16, 4903-4910; (d) N. Hafezi and J.-M. Lehn, J. Am. Chem. Soc., 2012, 134, 12861-12868; (e) G. Vantomme, S. M. Jiang and J.-M. Lehn, J. Am. Chem. Soc., 2014, 136, 9509-9518; corrigendum: J. Am. Chem. Soc., 2015, 137, 3138-3138 and J. Am. Chem. Soc., 2018, 140, 1179-1180; (f) G. Vantomme, N. Hafezi and J.-M. Lehn, Chem. Sci., 2014, 5, 1475-1483; $(g)$ J. Holub, G. Vantomme and J.-M. Lehn, J. Am. Chem. Soc., 2016, 138, 11783-11791; (h) J. J. Armao IV and J.-M. Lehn, Angew. Chem., Int. Ed., 2016, 55, 13450-13454; (i) S. Dhers, J. Holub and J.-M. Lehn, Chem. Sci., 2017, 8, 2125-2130; (j) L. Yue, S. Wang, A. Cecconello, J.-M. Lehn and I. Willner, ACS Nano, 2017, 11, 12027-12036; $(k)$ G. W. Men and J.-M. Lehn, J. Am. Chem. Soc., 2017, 139, 2474-2483; (l) S. Wang, L. Yue, Z. Shpilt, A. Cecconello, J. S. Kahn, 
J.-M. Lehn and I. Willner, J. Am. Chem. Soc., 2017, 139, 96629671; (m) M. Herder and J.-M. Lehn, J. Am. Chem. Soc., 2018, 140, 7647-7657.

4 For a chemical interaction network, see: S. Ghosh, P. Mukhopadhyay and L. Isaacs, J. Syst. Chem., 2010, 1, 1-6. 5 For recent reviews about systems chemistry, see, for instance:(a) S. A. Kauffman, ACS Symp. Ser., 2007, 981, 310-324; (b) R. F. Ludlow and S. Otto, Chem. Soc. Rev., 2008, 37, 101-108; (c) J. R. Nitschke, Nature, 2009, 462, 736-738; (d) J. J. P. Peyralans and S. Otto, Curr. Opin. Chem. Biol., 2009, 13, 705-713; (e) R. A. R. Hunt and S. Otto, Chem. Commun., 2011, 47, 847-858; (f) O. Taran and G. von Kiedrowski, in Chemical Synthetic Biology, ed. P. L. Luisi and C. Chiarabelli, John Wiley \& Sons, Chichester, 2011, pp. 289-319; (g) J. Huck and D. Philp, in Supramolecular Chemistry: From Molecules to Nanomaterials, ed. P. A. Gale and J. W. Steed, John Wiley \& Sons, Chichester, 2012, pp. 1415-1445; (h) N. Giuseppone, Acc. Chem. Res., 2012, 45, 2178-2188; (i) J. Li, P. Nowak and S. Otto, J. Am. Chem. Soc., 2013, 135, 9222-9239; (j) B. Grzybowski, S. Otto and D. Philp, Chem. Commun., 2014, 50, 14924-14925; (k) E. Mattia and S. Otto, Nat. Nanotechnol., 2015, 10, 111-119.

6 M. N. Chaur, D. Collado and J.-M. Lehn, Chem.-Eur. J., 2011, 17, 248-258.

7 (a) A. Choudhury, B. Geetha, N. R. Sangeetha, V. Kavita, V. Susila and S. J. Pal, Coord. Chem., 1999, 48, 87-95; (b) S. Choudhary and J. R. Morrow, Angew. Chem., Int. Ed., 2002, 41, 4096-4098; (c) P. V. Bernhardt, P. Chin, P. C. Sharpe and D. R. Richardson, Dalton Trans., 2007, 30, 3232-3244; (d) C. F. Chow, S. Fujii and J.-M. Lehn, Angew. Chem., Int. Ed., 2007, 46, 5007-5010; (e) X. Y. Cao, J. Harrowfield, J. Nitschke, J. Ramirez, A. M. Stadler, N. Kyritsakas-Gruber, A. Madalan, K. Rissanen, L. Russo, G. Vaughan and J.-M. Lehn, Eur. J. Inorg. Chem., 2007, 18, 2944-2965.

8 (a) G. Palla, A. Mangia and G. Predieri, Ann. Chim., 1984, 74, 153-158; (b) D. G. Belov, B. G. Rogachev, L. I. Tkachenko, V. A. Smirnov and S. M. Aldoshin, Russ. Chem. Bull., 2000, 49, 666-668; (c) V. V. Syakaev, S. N. Podyachev, B. I. Buzykin, S. K. Latypov, W. D. Habicher and A. I. Konovalov, J. Mol. Struct., 2006, 788, 55-62.

9 For a selection of reviews specifically on dynamic covalent/ combinatorial chemistry, see, for instance:(a) J.-M. Lehn, Chem.-Eur. J., 1999, 5, 2455-2463; (b) S. J. Rowan, S. J. Cantrill, G. R. Cousins, J. K. M. Sanders and J. F. Stoddart, Angew. Chem., Int. Ed., 2002, 41, 898-952; (c) P. T. Corbett, J. Leclaire, L. Vial, K. R. West, J.-L. Wietor, J. K. M. Sanders and S. Otto, Chem. Rev., 2006, 106, 36523711; (d) S. Ladame, Org. Biomol. Chem., 2008, 6, 219-226; (e) Dynamic Combinatorial Chemistry, ed. B. L. Miller, Wiley, Chichester, 2010; (f) J. N. H. Reek and S. Otto, Dynamic
Combinatorial Chemistry, Wiley-VCH, Weinheim, 2010; $(g)$ R. A. R. Hunt and S. Otto, Chem. Commun., 2011, 47, 847855; (h) M. E. Belowich and J. F. Stoddart, Chem. Soc. Rev., 2012, 41, 2003-2024; (i) J. W. Li, P. Nowak and S. Otto, J. Am. Chem. Soc., 2013, 135, 9222-9239; (j) A. Herrman, Chem. Soc. Rev., 2014, 43, 1899-1933; (k) Dynamic Covalent Chemistry: Principles, Reactions and Applications, ed. W. Zhang and Y. Jin, Wiley, 2018.

10 (a) E. T. Kool, D. H. Park and P. Crisalli, J. Am. Chem. Soc., 2013, 135, 17663-17666; (b) D. K. Kölmel and E. T. Kool, Chem. Rev., 2017, 117, 10358-10376.

11 (a) E. H. Cordes and W. P. Jencks, J. Am. Chem. Soc., 1962, 84, 826-831; (b) W. P. Jencks, Catalysis in Chemistry and Enzymology; McGraw-Hill, New York, 1969, pp. 493-496; (c) A. Dirksen, S. Dirksen, T. M. Hackeng and P. E. Dawson, J. Am. Chem. Soc., 2006, 128, 15602-15603; (d) V. T. Bhat, A. M. Caniard, T. Luksch, R. Brenk, D. J. Campopiano and M. F. Greaney, Nat. Chem., 2010, 2, 490-497; (e) M. Rashidian, M. M. Mahmoodi, R. Shah, J. K. Dozier, C. R. Wagner and M. Distefano, Bioconjugate Chem., 2013, 24, 333-342.

12 (a) S. E. Livingstone and J. E. Oluka, Transition Met. Chem., 1978, 3, 261-267; (b) O. Pouralimardan, A.-C. Chamayou, C. Janiak and H. Hosseini-Monfared, Inorg. Chim. Acta, 2007, 360, 1599-1608; (c) A.-M. Stadler and J. Harrowfield, Inorg. Chim. Acta, 2009, 362, 4298-4314; (d) N. A. Mangalam, S. Sivakumar, S. R. Sheeja, M. R. Prathapachandra Kurup and E. R. T. Tiekink, Inorg. Chim. Acta, 2009, 362, 4191-4197; (e) A. A. Recio Despaigne, J. G. da Silva, A. C. M. do Carmo, F. Sives, O. E. Piro, E. E. Castellano and H. Beraldo, Polyhedron, 2009, 28, 3797-3803; $(f)$ N. A. Mangalam, S. R. Sheeja and M. R. Prathapachandra Kurup, Polyhedron, 2010, 29, 33183323; (g) M. S. Shongwe, S. H. Al-Rahbi, M. A. Al-Azani, A. A. Al-Muharbi, F. Al-Mjeni, D. Matoga, A. Gismelseed, I. A. Al-Omari, A. Yousif, H. Adams, M. J. Morris and M. Mikuriya, Dalton Trans., 2012, 41, 2500-2514.

13 (a) D. J. van Dijken, P. Kovaříček, S. P. Ihrig and S. Hecht, J. Am. Chem. Soc., 2015, 137, 14982-14991; (b) I. Cvrtila, H. Fanlo-Virgós, G. Schaeffer, G. M. Santiago and S. Otto, J. Am. Chem. Soc., 2017, 139, 12459-12465.

14 (a) N. Giuseppone, J.-L. Schmitt and J.-M. Lehn, Angew. Chem., Int. Ed., 2004, 43, 4902-4906; (b) N. Giuseppone, J.-L. Schmitt, E. Schwartz and J.-M. Lehn, J. Am. Chem. Soc., 2005, 127, 5528-5539; (c) N. Giuseppone, J.-L. Schmitt and J.-M. Lehn, J. Am. Chem. Soc., 2006, 128, 16748-16763.

15 G. Vantomme, N. Hafezi and J.-M. Lehn, Chem. Sci., 2014, 5, 1475-1483.

16 (a) S. Fujii and J.-M. Lehn, Angew. Chem., Int. Ed., 2009, 48, 7635-7638; (b) See also Fig. 11 in J.-M. Lehn, Adv. Polym. Sci., 2013, 261, 155-172. 